اثر إستخدام إستراتيجية محطات التعلم في تنمية الأستيعاب المفاهيمي في العلوم لدي تلاميذ المرحلة الإعدادية

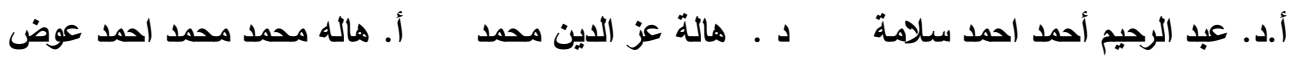

\title{
اثر إستخدام إستراتيجية مهطات التعلم في تنمية الأستيعاب المفاهيسي في العلوم لدي تلاميذ المرحلة الإعدادية
}

د. هالة عز الدين محمد

قسم المناهج وطرق التدريس

كلية التربية - جامعة جنوب الوادي

halaezzeldin@yahoo.com
أ.د. عبد الرحيم أحمد احمد سلامة

قسم المناهج وطرق التدريس كلية التربية - جامعة جنوب الوادي

Abdulrahem2020@hotmail.com

أ. هاله محمد محمد احمد عوض

طالبة ماجستير قسم المناهج وطرق التدريس

Halola531@gmail.com 
اثر إستخدام إستراتيجية محطات التعلم في تنمية الأستيعاب المفاهيمي في العلوم لاي تلاميذ المرحلة الإعدادية

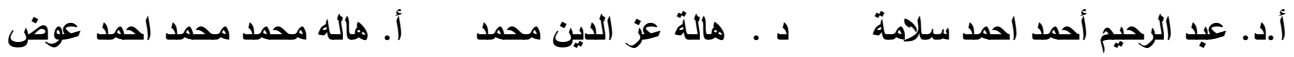

\section{اثر إستخدام إستراتيجية محطات التعلم في تنمية الأستيعاب المفاهيمي في العلوم لاي تلاميذ المرحلة الإعدادية}

\author{
د. هالة عز الدين محمد \\ قسم المناهج وطرق التدريس \\ كلية التربية -جامعة جنوب الوادي \\ halaezzeldin@yahoo.com
}

أ.د. عبد الرحيم أحمد احمد سلامة

$$
\text { قسم المناهج وطرق التدريس }
$$

كلية التربية -جامعة جنوب الوادي

Abdulrahem2020@hotmail.com

\section{أ. هاله محمد محمد احمد عوض}

طالبة ماجستير قسم المناهج وطرق التدريس

\section{Halola531@gmail.com}

المستخلص: - - 1

هدف البحث الحالي تعرف اثز استخدام استراتيجية محطات التعلم في تتمية

الاستيعاب المفاهيمي في العلوم لتلاميذ المرحلة الاعدادية حيث تم إعادة صياغة وحدة "الطاقة" المقررة على تلاميذ الصف الاول من المرحلة الاعدادية في مادة العلوم

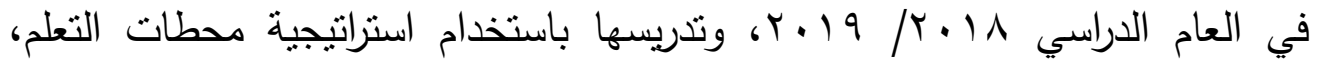
وتكونت عينة البحث من (VY) طالبة، قسمت لمجموعنين: الضابطة وتكونت من (rV) طالبة درست بالطريقة التقليدية، والتجربيية ونكونت من (0r) طالبة درست باستخدام استراتيجية محطات التعلم، وتم تطبيق أداة البحث المتمثلة في: اختبار الاستيعاب المفاهيمي، على أفراد مجموعتي البحث بعديًا.وتوصل البحث إلى انه توجد فروق ذات دلاله احصائية عند مستوى (0...) بين متوسطات درجات طالبات المجموعه التجريبة والمجموعه الضابطة في التطبيق البعدي لاختبار الاستيعاب المفاهيمي لصالح المجموعه التجريبية، وفي ضوء تللك النتائج تم تقديم مجموعة من التوصيات والمقترحات. الكلمات المفتاحية: استراتيجية محطات التعلم، الاستيعاب المفاهيمي. 
اثث إستخدام إستراتيجية محطات التطلم في تنمية الأستيعاب المفاهيمي في العوم لاي تلاميذ المرحلة الإعادية

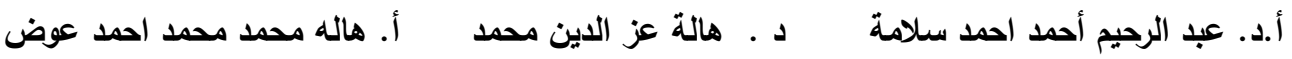

\title{
Effect of Using the Learning Stations Strategy on Developing First Prep School Students' Conceptual Understanding in Science
}

\author{
Prof.Dr. Abdulrahem ahmad salama \\ Curricula \& Science Instruction Dept \\ Qena Faculty of Education \\ South Valley University \\ Abdulrahem2020@hotmail.com
}

\author{
Dr.Hala Ezz-eldin Mohamed \\ Curricula \& Science Instruction Dept \\ Qena Faculty of Education \\ South Valley University \\ halaezzeldin@yahoo.com
}

\section{Hala Mohamed Mohamed Ahmed \\ Mster Student Curricula \& Instruction Dept. \\ Halola531@gmail.com}

\begin{abstract}
This research aimed to investigating the effect of using the of learning stations strategy on developing first prep female student's conceptual understanding of learning science. The unit of "energy" studied by first year prep female students in science in the academic year 2018/2019 was restructured and taught using the learning stations strategy. The participants of the study were (72) female student . They were divided into two groups: a control group (37) student, who studied the unit through the traditional method and an experimental on (37) student who studied the unit through the (learning stations strategy). The instrument of the study; the test of conceptual understanding was post -administered to both group . The results of research revealed significant differences at ( 0.05) between the mean scores of the control and experimental group on the post test conceptual understanding favoring the experimental group. In the light of these results,some recommendations \& suggestion were presented.
\end{abstract}

Key-words: learning stations strategy , conceptual understanding 
اثر إستخدام إستراتيجية محطات التعلم في تنمية الأستيعاب المفاهيمي في العلوم لاي تلاميذ المرحلة الإعدادية

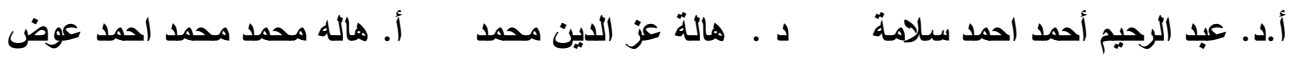

\section{مقدمة:}

في عصر العلم والتكنولوجيا والتغيرات السريعة والمستمرة تشهد التربية العلمية وتدريس العلوم اهتماماً كبيراً وتطورا نحو الأفضل بشكل مستمر، وذلك لمواكبة هذه ونه التطورات والتكيف معها واستيعاب مفاهيمها بما يتتاسب مع حاجات الفرد والمجتمع. وقد أصبح التركيز في التعليم على أن يصل بالمتعلم إلى توليد المعرفة لديه بدلاً من تلقيها وحفظها جاهزةً.

لقد أكد علماء التربية على أن أساسيات المعرفة هي أحد الحلول التي قد تكون

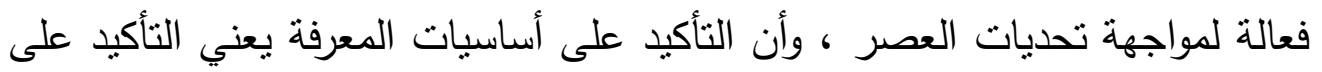
المفاهيم والمبادئ التي تتكل هذه المعرفة، والتي في ضوئها يمكن فهم العديد من

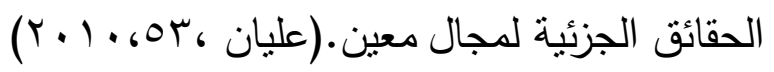

وتعد المفاهيم العلمية من نواتج العلم التي بواسطتها يتم تتظيم المعرفة العلمية

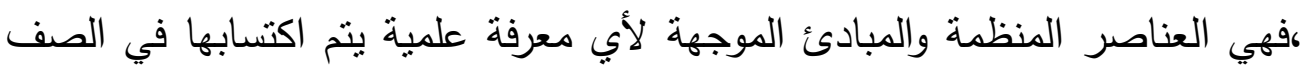
الدراسي، أو المختبر أو أي مكان آخر ، ولذلك أصبح التعلم ذو المعني للمفاهيم العلمية

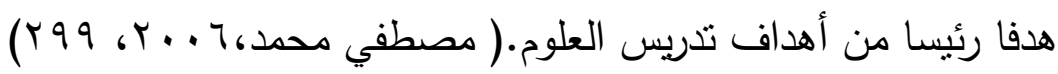

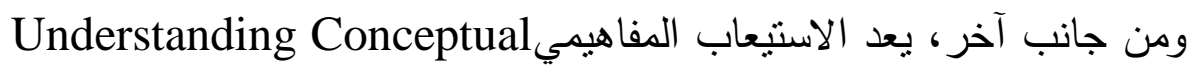
أحد جوانب التعلُّم المهمة التي لم تأخذ حقها في كثير من المواد الدراسية، كما أنه من نواتج التعلُّم التي أشارت إليها المعايير العالمية لتعليم العلوم(Russell,2002). ولقد ظهرت أهمية تحديد جوانب أو مظاهر أساسية للفهم يمكن من خلالها وصف جوانب الفهر المتعمق عند المتعلمين، وهذا ما قام به ويجنز ومكتاي حيث اقترحا ستة أوجه يكثفان بها فهم الطالب (Wiggins and Mctighe, 1998) لما تعلمه، وأطلقا عليها( الأوجه الستة للفهم)، وهي :الثرح، التقسير، التطبيق، الروئة / المنظور، التعاطف، المعرفة الذاتية، وتتير هذه الأوجه إلى ما يمكن أن يكثف به المعلم 
اثثر إستخدام إستراتيجية محطات التطلم في تنمية الأستيعاب المفاهيمي في العلوم لاي تلاميذ المرحلة الإعدادية

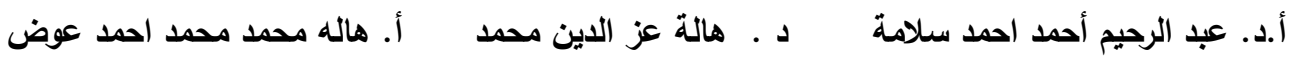

عن فهم طالباته، ليقرر ما إذا كانوا قد فهموا ما تعلموه، أو أنهم لم يفهموه. (ويجنز

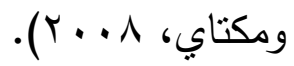

وعلى الرغم من أهمية استيعاب الطلاب للمفاهيم العلمية فان بعض الدراسات

أكدت على تدني الاستيعاب المفاهيمى لدي الطالبات وانه يمكن تتميته من خلال نماذج واستراتيجيات تدريسية مختلفة، ومن هذه الدراسات دراسة كولمنت Kalkanis et ) (سالم، (Clement,2003)

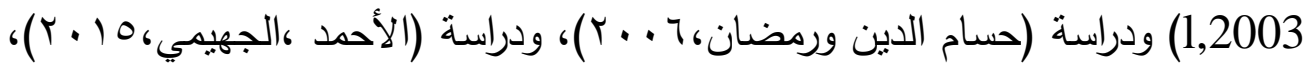

$$
\text { ودراسة (المغربي، ع ا • (ب). }
$$

وقد أرجعت تلك الدراسات هذا التدني في فهم الطالبات للمفاهيم العلمية إلى استخدام معلمي العلوم للطرائق التقليدية في التّريس والتي تعتمد على تقديم المعلم للمعارف، وينصت المتعلمون خلالها إلى ما يقوله المعلم، وأن هذه الطرائق لا تسهم في ايجاد تعلم حقيقي، الأمر الذي دعا الباحثين إلى البحث عن استراتيجيات وطرائق تدريسية تهدف في المقام الأول إلى تتمية ادراك المفاهيم العلمية. ومن أكبر التحديات التي تواجه المعلمين في مجال البحث عن استراتيجيات التدريس المناسبة هو التتوع الكبير بين مستويات المتعلمين، وإن أكبر تحد يواجهه المعلم هو محاولة الاستجابة للطيف الواسع والمتزايد من الاحتياجات والخلفيات والقدرات وأنماط التعلم المتمايزة لدي المتعلمين. (Heacox,2002 ) واستجابةً لتلك التحديات والمتطلبات فقد ظهر مفهوم التعليم المتمايز ، حيث ذكرت كوجك وآخرون (1 . . r) أن فكرة تتويع التدريس بدأت تأخذ مكانتها منذ العام 1919 حين أعلنت وثيقة حقوق الطفل، ومن ثم في العام • 199 في المؤتمر العالمي للتربية الذي عقد في جومتيان وتلاه مؤتمر داكار عام . . . . . والذي أوصى بالتعليم للتميز و التميز للجميع، وقد ركزت نوصيات تلك المؤتمرات على الأخذ في الاعتبار الاختلافات بين المتعلمين ، في الخبرة والثقافة والبيئة والاستعداد والقدرات والاهتمامات والميول والذكاءات، وأنه من الضروري تتويع طرق التدريس بحيث يتمكن جميع 
اثثر إستخدام إستراتيجية محطات التطلم في تنمية الأستيعاب المفاهيمي في العلوم لاي تلاميذ المرحلة الإعدادية

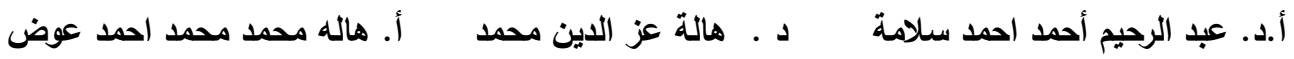
المتعلمين من الحصول على تعليم يتواءم مع خصائصهم ، ويحقق لكل منهم أقصى درجات النجاح و الانجاز في إطار إمكاناته وقدراته. وهناك العديد من الإستراتيجيات الحديثة التي تُصنّف تحت أثنكال التدريس المتمايز ومن خلالها يمكن مراعاة التمايز والاختلاف بين المتعلمين وتحقيق الأهداف

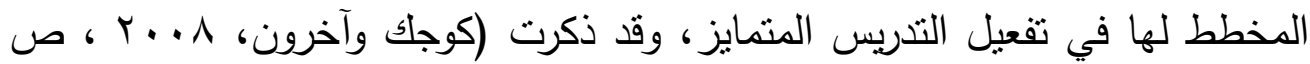
9 1 (1) مجموعة من نلك الاستراتيجيات ومنها: إستراتيجية محطات التعلم، وإستراتيجيات ضغط محتوى المنهج،والأنشطة المتدرجة،والمجموعات المرنة،وعقود التعلم، والأنشطة

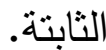

"Denise" وتُعد إستراتيجية محطات التعلم والتي قام بتصميمها دينيس جون

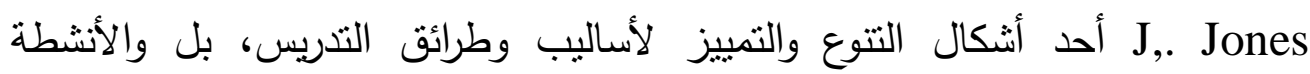
التعليمية المختلفة، حيث يتحول فيها شكل الفصل عن الثكل التقليدي إلى بعض كل الطاولات التي يطوف حولها مجموعات الطلبة وفقاً لنظام محدد، وتعتبر كل منها محطة تعليمية مزودة بأدوات ومواد تعليمية وأوراق عمل لممارسة مهمة تعليمية كنوع من أنواع الأنشطة التعليمية المختلفة والمتتوعة، فهناك العديد من المحطات منل: المحطة الاستقصائية الاستكثافية المحطة القرائية، والمحطة الصورية،والمحطة السمعية البصرية ،والمحطة الالكترونية، والمحطة الاستشارية، ومحطة متحف الثمع، ومحطة الـ (نعم) والـ (لا). (Denise J., Jones, 2007) وقد قام عدد من الباحثين بإجراء دراسات عن استخدام إستراتيجية محطات التعلم في تحسين عملية التعلم وفاعليتها في تحصيل المعرفة العلمية للطالبات

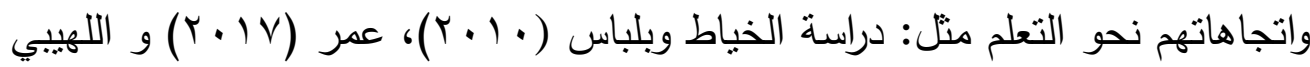

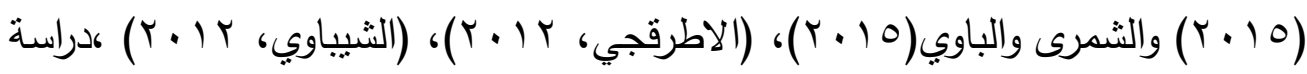

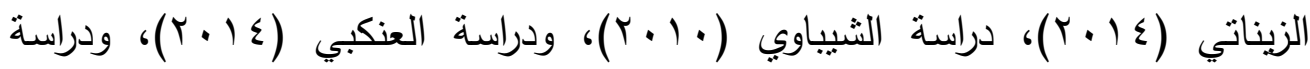

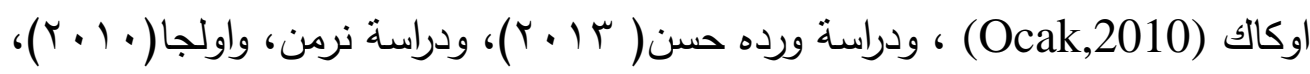
وقد أظهرت نتائجها فعالية محطات التعلم في تحقيق الكثير من المخرجات التعليمية. 
اثر إستخدام إستراتيجية محطات التعلم في تنمية الأستيعاب المفاهيمي في العلوم لاي تلاميذ المرحلة الإعدادية

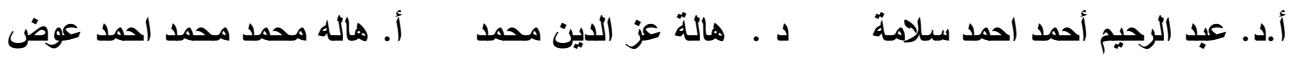

$$
\text { مشكلة الدراسة :- مئمة }
$$

المتأمل لواقع تدريس العلوم في المراحل التعليمية المختلفة يلاحظ أنه يعانى من مشكلات تتمنل في تدنى تحصيل واستيعاب الطالبات للمفاهيم العلمية وهذا ما أكدته بعض الدراسات التي تم الإشارة إليها،إضافة إلى ضعف دافعيتهم نحو دراسة العلوم والذي يظهر جليا من خلال تزايد أعداد الطالبات الملتحقين بالقسم الأدبي في الإنساء المرحلة الثانوية.

ومن ناحية أخري يلاحظ أن الطرق المتبعة في تدريس العلوم لا تراعى النتوع والاختلافات الموجود بين المتعلمين، كما أن المحتوى العلمي لمقررات العلوم مزدحم بالمفاهيم العلمية التي تحتاج إلى طريقة تدريسية فعالة تثير دافعية الطالبات نحو

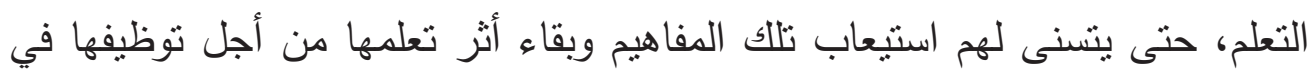
مواقف الحياة من أجل تفسير كثير من الظواهر الحياتية. ومما سبق يمكن بلورة مشكلة الدراسة الحالية في تدني استيعاب المفاهيم

$$
\begin{aligned}
& \text { العلمية لدي طالبات المرحلة الإعدادية. } \\
& \text { أسئلة الاراسة: }
\end{aligned}
$$

تحاول الدراسة الاجابة على السؤال التالي:

- ما أثر استخلام إستراتيجية محطات التعلم في تنمية الاستيعاب المفاهيمي

لاى تلاميذ المرحلة الاعدادية ؟

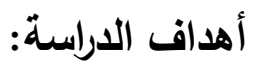

$$
\text { تهدف الدراسة إلي :- }
$$

- التعرف على أثر استخدام إستراتيجية محطات التعلم في تتمية الاستيعاب المفاهيمي لاى تلاميذ المرحلة الاعدادية. 
اثر إستخدام إستراتيجية محطات التعلم في تنمية الأستيعاب المفاهيمي في العلوم لدي تلاميذ المرحلة الإعدادية

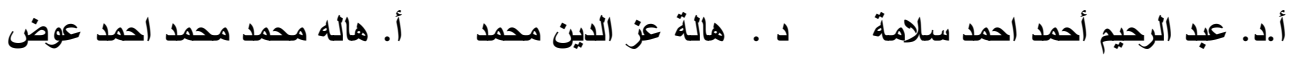

أهمية الدراسة:

قد تفيد الدراسة في:

! . يمكن النظر لهذه الدراسة باعتبارها إضافة نوعية في مجال تطوير بعض طرق التدريس الجديدة والتي تحقق التعليم المتمايز ، فهي استجابة منطقية لمواجهة تباين الطالبات في الفصل الواحد ليناسب اختلافهم وتمايزهم وفقاً لاحتياجاتهم وميولهم واستعدادهم وأنماط تعلمهم. r. تشجيع معلمي العلوم بالمرحلة الإعدادية على استخدام صيغ تدريسية حديثة وهئة كإستراتيجية محطات التعلم والتي تعمل على قيام الطالبات بأنشطة منتوعة تتاسب احتياجاتهم وتسنتير انتباههم ودافعيتهم للتعلم؛ الأمر الذي قد يؤثر بالإيجاب على استيعابهم للمفاهيم العلمية. r. تزويد الباحثين باختبار للاستيعاب المفاهيمى لبعض المفاهيم العلمية، مما قد يفيدهم في مجال تدريس العلوم. ع. تزويد معلمي العلوم والمشرفين التربويين بدليل يمكن الاسترشاد به في استخدام إستراتيجية محطات التعلم في تدريس العلوم و تتمية فهم المفاهيم العلمية. فرض الدراسة: تسعى الدراسة إلى اختبار صحة الفرض التالي: - لا يوجد فرق ذو دلالة إحصائية عند مستوى ( 10 إ. . . ) بين متوسطي درجات تلميذات المجموعة التجريبية ( التي درست باستراتيجية محطات التعلم) والمجموعة الضابطة ( التي درست بالطريقة التقليدية) في التطبيق البعدي لاختبار الاستيعاب المفاهيمي. حدود الدراسة:

تلتزم الدراسة الحالية بالحدود التالية : 1. الاقتصار على تدريس الوحدة الثانية "الطاقة " والمقررة في كتاب العلوم للصف

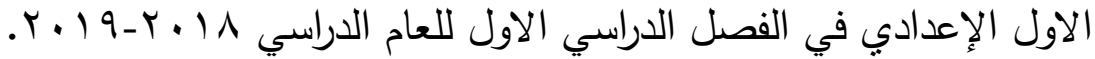


اثر إستخدام إستراتيجية محطات التعلم في تنمية الأستيعاب المفاهيمي في العلوم لدي تلاميذ المرحلة الإعدادية

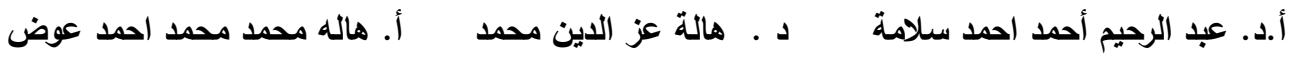
r. عينة من تلاميذ الصف الاول الاعدادي بمدرسة الاعداديه بنات بإدارة قنا التعليمية. r. توظيف أربعة أنواع من محطات التعلم: (الاستكثافية، والقرائية، والصورية، والالكترونية) في تدريس الوحدة المختارة.

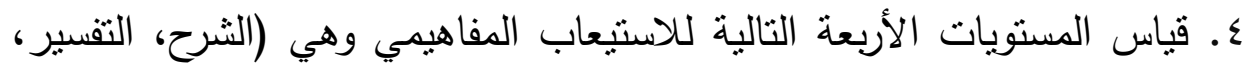
التطبيق، اتخاذ منظور ). مواد وأدوات الدراسة: - - يستخدم في هذه الدراسة المواد التالية : 1. دليل المعلمة لتدريس الوحدة المختارة باستخدام إستراتيجية محطات التعلم. r. كتيب أوراق عمل التلميذة لدراسة الوحدة باستخدام إستراتيجية محطات التعلم. - - ويستخدم في هذه الدراسة أداة تتمنل في اختبار الاستيعاب المفاهيمي لقياس استيعاب المفاهيم العلمية لاى تلاميذ الصف الاول بالمرحلة الاعدادية في

$$
\text { مصطلحات الدراسةة " الطاقة " من إعداد الباحثة" . }
$$

\section{learning stations محطات التعلم}

يعرفها جونز (Jones , 2007) بأنها إستراتيجية تدريسية تتنقل فيها مجموعة صغيرة من الطلبة عبر سلسلة من المحطات مما يسمح للمعلمين اعتماد وسائل محددة تتيح لكل طالب تأدية كل النشاطات عبر التناوب على المحطات المختلفة. (Jones,2007,16-21)

وتعرف بأنها: إستراتيجية تضم مجموعة من الأنشطة العلمية يتم ممارستها داخل غرفة الصف أو في المختبر من قبل الطالبات أنفسهم وتكون منوعة منها الاستكثافية البسيطة والقرائية والالكترونية والصورية وغيرها ويمكن وصف هذه

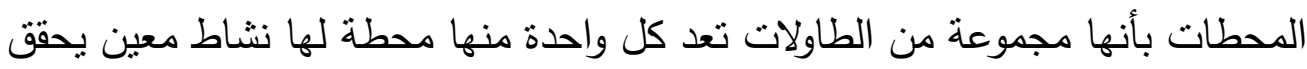

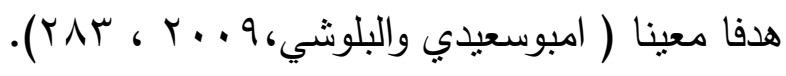


اثر إستخدام إستراتيجية محطات التعلم في تنمية الأستيعاب المفاهيمي في العلوم لاي تلاميذ المرحلة الإعدادية

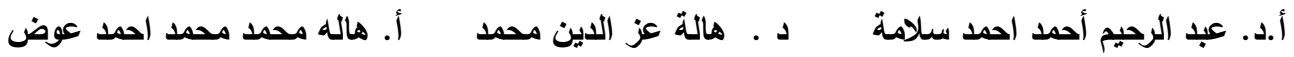

وتعرف إجرائيا بأنها: إستراتيجية تدربسية تقوم على مجموعة من المحطات

يقوم فيها طالبات الصف الثاني الإعدادي بالمرور عليها وممارسة الأنشطة التعليمية الموجودة بكل منها والتي قد تكون: استقصائية، قرائية، استكثافية، أو بصرية صورية، أو الكترونية.... .وغيرها، استتادا إلى أوراق العمل بإشراف المعلمة بهدف تتمبة الاستيعاب المفاهيمي ودافعتيهم لتعلم العلوم.

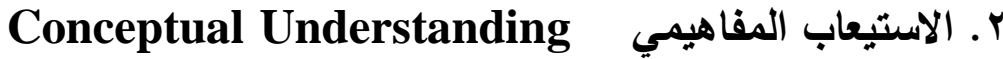

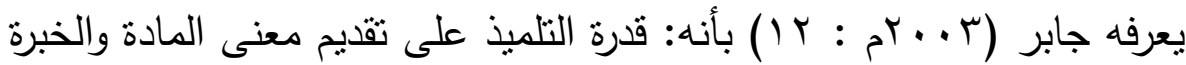
التعليمية، وتظهر في تفسير بعض أجزاء المادة، والتوسع فيها، ووضوح الأفكار، وتطبيقها في مواقف جديدة، وتصوير المشكلة وحلها بطرق مختلفة. وقد قدم ويجنز ، ومكتاي (Wiggins\&Mctighe, 2008) تعريفا عمليا للاستيعاب المفاهيمي وذلك من خلال تقديم المظاهر الستة للاستيعاب المفاهيمي والتي يمكن من خلالها وصف وتقييم مستوي الفهم المتعمق للمتعلمين وهي: - التوضيح Explain: أي يقدم أوصاف متقنة للظواهر والحقائق والبيانات . - التفسير Interpret: أي يقدم معنى لحدث، أو إعطاء ثرجمات ملائمة للمفاهيم والحقائق وربطها بأحداث واقعية. - - التطبيق Apply: أي يستخدم المعرفة بشكل فعال في ظروف وأوضاع جديدة. - - أتحاذ منظور Perspective: أي القدرة علي تقديم وجهات نظر نقدية . - المشاركة الوجدانية Empathy: أي يكون لديه المقدرة للاخول في عالم وأحاسيس الآخرين

- معرفة الذات Self-Knowledge: أي بدرك تأملاته وعاداته العقلية والثخصية التي تكون فهمه الخاص او تعوقه.

ويعرف الاستيعاب المفاهيمي إجرائيا في هذه الدراسة بأنه: قدرة طالبات الصف الثاني الإعدادي على توضيح المفاهيم العلمية المقدمة لهم في وحدة "الصوت والضوء" وتفسيرها وتطبيق ما اكتسبته من معارف في مواقف جديدة، وامتلاكها معرفة لذاتها 
اثر إستخدام إستراتيجية محطات التعلم في تنمية الأستيعاب المفاهيمي في العلوم لاي تلاميذ المرحلة الإعدادية

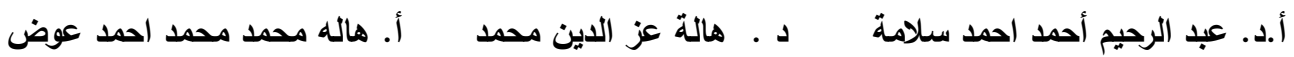

وطريقة تعلمها، وتقديم وجهة نظر نقدية مرتبطة بفهم تلك المفاهيم، ويقاس إحصائيا بالدرجة التي تحصل عليها الطالبة في اختبار الاستيعاب المفاهيمي المعد لذلك. إجراءات الدراسة:

ا. الاطلاع على الأدبيات والبحوث السابقة في مجال التعليم المتمايز وإستراتيجية محطات التعلم، والاستيعاب المفاهيمي وذلك لتحديد الإطار النظري والدراسات

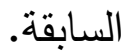
r. تحليل محتوي وحدة "الطاقة" من مقرر العلوم للصف الأول الإعدادي لتحديد المفاهيم العلمية المتضمنة. r. إعداد الوحدة المقترحة وإعادة صياغتها وفقا لاستراتيجيه محطات التعلم وتم إتباع الخطوات التالية في إعداد الوحدة المختارة: أ. إعداد دليل المعلمة، وكتيب أوراق عمل التلميذة لدراسة وحدة "الطاقة" باستخدام إستراتيجية محطات التعلم.

ب. عرض دليل المعلمة وكتيب أوراق العمل على مجموعة من المحكمين. ؟. إعداد أداة الدراسة والمتمتلة في اختبار الاستيعاب المفاهيمي، وتم التحقق من صدقه وثباته من خلال عرضه على مجموعة من المحكمين. ○. اختيار عينة الدراسة وتقسيمها إلى مجموعتين، إحداهما تمثل المجموعة التجريبية التي تدرس وفقالإستراتيجية محطات التعلم، والأخرى ضابطة وتدرس إنس

$$
\text { وفقا للطريقة المعتادة حاليا في المدارس. }
$$
T. الاعداد لتطبيق تجربة الدراسة وضبط بعض المتغيرات للتحقق من تكافؤ

$$
\text { مجموعتي الدراسة. }
$$

V. تدريس الوحدة المختارة للمجموعتين التجريبية والضابطة، وذلك باستخدام إستراتيجية محطات التعلم للمجموعة التجريبية والطريقة التقليدية للمجموعة الضابطة. - ابط 
اثر إستخدام إستراتيجية محطات التعلم في تنمية الأستيعاب المفاهيمي في العلوم لدي تلاميذ المرحلة الإعدادية

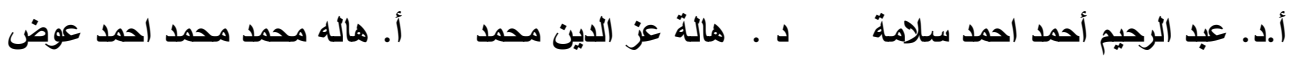
^. تطبيق أداة الدراسة على أفراد العينة المختارة (اختبار الاستيعاب المفاهيمي) بعديا.

9 9. إجراء التحليل الإحصائي للبيانات وتفسير النتائج في ضوء فرض الدراسة . • 1 ـ تقديم التوصيات والمقترحات في ضوء ما تسفر عنه نتائج الدراسة.

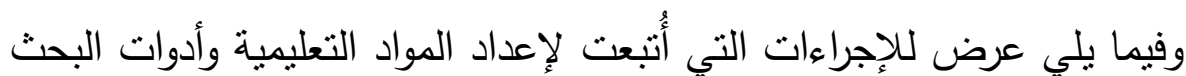
و ضبطها، و كذللك إجراءات تجربة البحث: أولاً: إعداد المواد التعليمية:

لتحقيق هدف البحث تم إعداد دليل المعلمة، وأوراق عمل الطالبه، وقد تم تتفيذ ذللك على النحو التالي: - التي 1. اختيار المحتوى العلمي: تم اختيار الوحدة الثانية (الطاقة) بالفصل الدراسي الاول مجالاً للبحث الحالي. r. تحليل المحتوى التعليمي لموضوعات وحدة (الطاقة): وذلك بهذف تحديد المفاهيم المتضدنة، وقد توصلت - نتيجة التحليل للمحتوى - إلى احتواء موضوعات الوحدة على 7 مفهوما.

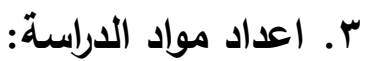
وتضمنت دليل المعلمة لتدريس الوحدة وفقا للاستراتيجية المقترحة، وكتيب أوراق عمل الطالبه، وتم ذلك كما يلي:

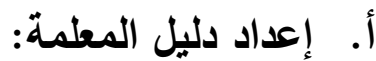

تم إعداد دليل للمعلمة لتدرس الوحدة المختارة في ضوء خطوات استراتيجية محطات التعلم يحتوى على الادوار والممارسات التي تقوم بها المعلمة أثناء تطبيق تجربة البحث، وقد روعي في هذا الدليل أن يتضمن ما يلي: - مقدمة تشمل فكرة عن إستراتيجية المحطات العلمية، وشرح لطبيعة كل محطة من المحطات العلمية التي تستخدم في كل درس من الدروس. - الأهداف العامة للوحدة، والأهداف السلوكية الخاصة بكل درس من الدروس. 
اثر إستخدام إستراتيجية محطات التعلم في تنمية الأستيعاب المفاهيمي في العلوم لاي تلاميذ المرحلة الإعدادية

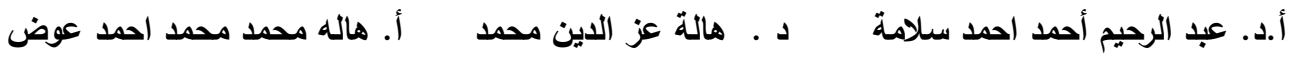
- وصفاً تفصيلياً لخطوات كل درس من الدروس، والدور الذي تقوم به المعلمة وفقاً لخطوات إستراتيجية المحطات العلمية، ووصف لكل الأنشطة التي سوف لهن لهن تتفذها الطالبات في كل محطة من المحطات. ب. إعداد أوراق عمل التلميذة: قامت الباحثة باعداد كتيب للطالبه يحتوي على (rاورقة عمل) لكل درس من دروس الوحدة، ويتضمن كل درس عدد (ع محطات ) تمر عليها الطالبات حيث ان كل محطة لها منطلبات، ومهام، وأنشطة، واسئلة للتقويم تمارسها الطالبات وفقاً لما هو هو موجود بأوراق العمل.

ج. ضبط دليل المعلم واورلق عمل الطالبات: عُرض دليل المعلمة وأوراق عمل الطالبات على مجموعة من السادة المحكمين المتخصصين في التربية العلمية وطرق تدريس العلوم ،.وقد اتفق السادة المحكمين على وضوح الأهداف العامة، والسلوكية الخاصة بكل درس، والعرض التذريسي لكل درس من الدروس وفقاً لإستراتيجية محطات التعلم، وكذلك الانشطة الواردة في أوراق العمل ،

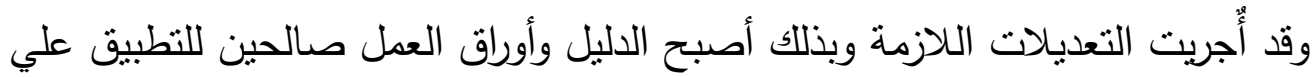
تجربة الدراسة. ثانياً - إعداد أداة البحث: البه: تطلب تحقيق هدف الدراسة إعداد أداة التقويم وتمثلت في: اختبار الاستيعاب المفاهيمي. وفيما يلي توضيح لكيفية إعداد اختبار الاستيعاب المفاهيمي: أُعد اختبار الاستيعاب المفاهيمي للاراسة وفق الخطوات التالية: أ. تحديد الهوف من الاختبار:

هدف الاختبار إلى قياس مستوى الاستيعاب المفاهيمي لدى تلاميذ المرحلة الاعدادية للمفاهيم العلمية المتضمنة في وحدة "الطاقة". 
اثر إستخدام إستراتيجية محطات التعلم في تنمية الأستيعاب المفاهيمي في العلوم لاي تلاميذ المرحلة الإعدادية

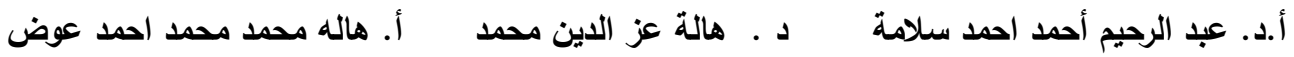

\section{ب. المستويات التي يقيسها الاختبار:}

بعد الاطلاع على بعض المراجع والدراسات السابقة التي اهتمت بقياس الاستيعاب المفاهيمي منل: دراسة (تامر شعبان دسوقي، Y I · )، ودراسة (مندور عبد

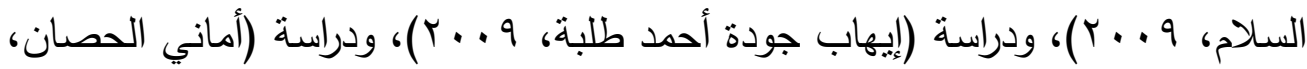

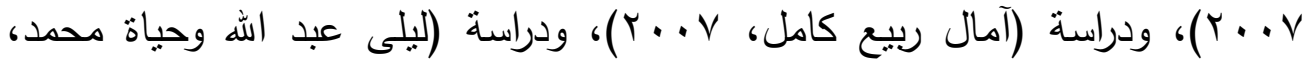

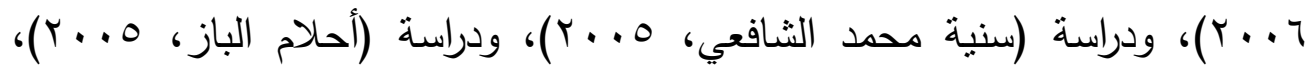
حُددت المستويات الاربعة التالية للاستيعاب المفاهيمي والمناسبة لتلاميذ المرحلة الاعدادية وهي: التوضيح، التفسير ، التطبيق، اتخاذ منظور ج. تحديد المفاهيم الأساسية التي يقيسها الاختبار من خلال ماقامت به الباحثة من تحليل لمحتوى وحدة "الطاقة" لتحديد المفاهيم العلمية الأساسية المتضندة بها، فقد تضمنت الوحدة (T) مفهوما علميا. د. تحديا نوع مفردات الاختبار وصياغتها:

صنيخت مفردات الاختبار من نوع أسئلة الاختيار من متعدد، وحيث تكونت كل مفردة من مقدمة (جذع)، ويتبعها إجابة صحيحة وثلاث بدائل يختار الطالب منها الإجابة الصحيحة، وقد روعي فيها شروط إعداد هذا النوع من الأسئلة، وقد اشتمل

$$
\text { الاختبار في صورته الأولية على ( • ع) مفردة. }
$$

تضمنت صفحة التعليمات بيان الهدف من الاختبار، وذلك بالإضافة إلى مجموعة من التعليمات التي تبين للطالبة كيفية الإجابة عن مفردات الاختبار، وزمن الاختبار ، وضرورة الإجابة عن جميع الأسئلة، وإعطاء مثال مجاب عنه لتوضيح كيفية الإجابة عن الأسئلة.

$$
\text { و. إعداد ورقة الإجابة ونظام تقدير الدرجات: }
$$

صمدت ورقة الإجابة منفصلة عن كراسة الأسئلة، ووضع نظام تقدير الدرجات في هذا الاختبار؛ بحيث تُعطى درجة واحدة فقط في حالة الإجابة الصحيحة للمفردة، و (صفر) في حالة الإجابة غير الصحيحة. 
اثر إستخدام إستراتيجية محطات التعلم في تنمية الأستيعاب المفاهيمي في العلوم لدي تلاميذ المرحلة الإعدادية

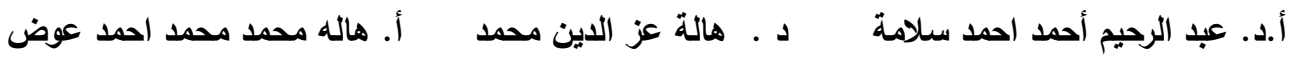

$$
\text { ز. ـ مساب صدق الاختبار: }
$$

للتأكد من صدق الاختبار تم عرضه في صورته الأولية على مجموعة من المحكمين من المتخصصين في مجال مناهج وطرق تدريس العلوم، ومشرفي ومعلمي العلوم وذللك لإبداء آرائهم حول مدى مناسبة الاختبار لمستوى تلاميذ المرحلة الاعدادية وصلاحية مفرداته لقياس مستوبات الاستيعاب المفاهيمي التي حُددت، وأُجريت بعض الُّ التعديلات في ضوء آراء السادة المحكمين.

$$
\text { ح. التجريب الاستطلاعي للاختبار }
$$

طبق الاختبار على مجموعة استطلاعية من طالبات الصف الثاني الاعدادي بمدرسة "قنا الاعدادية بنات بإدارة قنا التعليمية " ممن سبق لهم دراسة الوحدة ، وذللك

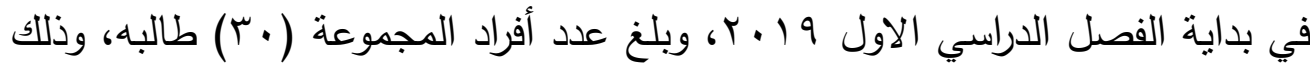
لتحديد كل sن:

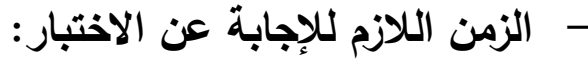

حُسب الزمن اللزم للإجابة عن الاختبار من خلال حساب متوسط الزمن الذي استغرقه أول طالبه انتهت من الإجابة عن أسئلة الاختبار ، والزمن الذي استغرقته آخر طالبه انتهت من الإجابة عن أسئلة الاختبار كوكان المتوسط الحسابي للزمن( • م)دقيقة. - - - مساب ثبات الاختبار : -

تم التحقق من ثبات الاختبار عن طريق التجزئة النصفية حيث بلغت قيمة معامل الارتباط بين درجات نصفي الاختبار ( V7 V • ) ) وبلغت قيمة ثبات سبيرمان

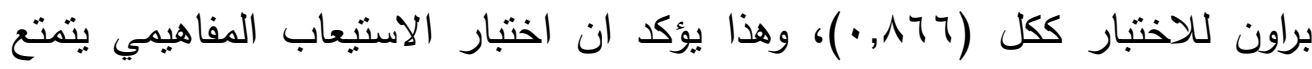
بمعامل ثبات مرتفع، وبعطي ثقة كبيرة في نتائج تطبيقة على تلاميذ المرحلة الاعدادية. - - حساب معاملات السهولة ومعاملات التمييز:

تم حساب معاملات السهولة لمفردات الاختبار، وقد تراوحت بين (عب, . -

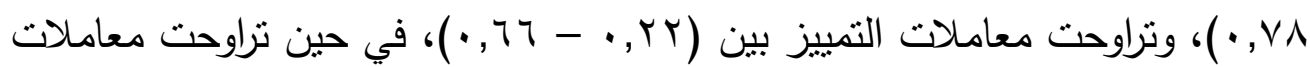

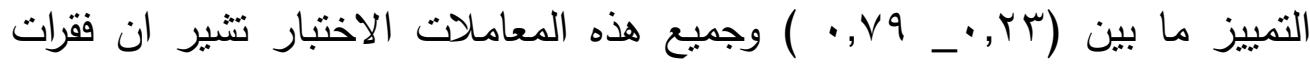
الاختبار تتمتع بمعامالت صعوبة وتمبيز مناسبة. 
اثر إستخدام إستراتيجية محطات التعلم في تنمية الأستيعاب المفاهيمي في العلوم لاي تلاميذ المرحلة الإعدادية

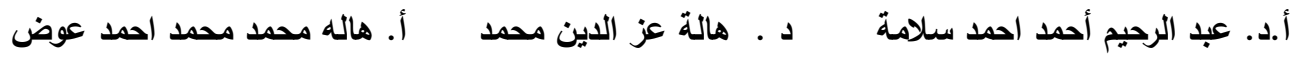

\section{ط. الصورة النهائية للاختبار:}

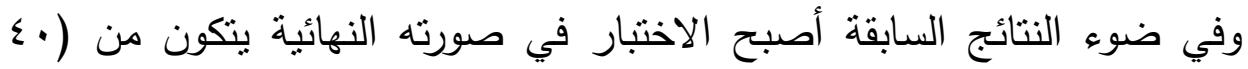
مفردة)، وصالحا للاستخدام، وجدول (1) يبين توزيع مفردات الاختبار على موضوعات الوحدة وفي مستويات الاستيعاب المفاهيمي الأربعة.

$$
\text { جدول (1) }
$$

مواصفات اختبار الاستيعاب المفاهيمي في العلوم

\begin{tabular}{|c|c|c|c|c|c|c|c|}
\hline الأوزان & مجموع & & ب المفاد & ويات الاستت & & ت & \\
\hline النسبية & الاسئلة & اتخاذ القرار & التطبيق & التفسير & التوضيح & 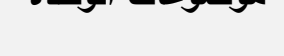 & r \\
\hline$\% 00$ & Yr & $r$ & $\varepsilon$ & 0 & 1. & مصادر الطاقة & 1 \\
\hline$\% r$. & $\Lambda$ & 1 & Y & 1 & $\varepsilon$ & تحولات الطاقة & r \\
\hline$\%$ Yo & 1. & r & r & 1 & 0 & الطاقة الحرارية & $r$ \\
\hline$\% 1 \ldots$ & $\varepsilon$. & 7 & $\Lambda$ & V & 19 & مجموع الاسئلة & \\
\hline & $\% 1 \ldots$ & $\% 10$ & $\% r$. & $\% \backslash \vee, 0$ & $\% \leqslant V, 0$ & المعبرفية للمستويات & \\
\hline
\end{tabular}

رابعاً: التصميم التجريبي وإجراءات التجرية:

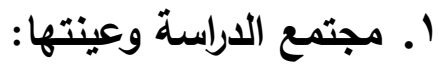
مجتمع الاراسة: تلاميذ المرحلة الاعدادية في المدارس الاعدادية للعام

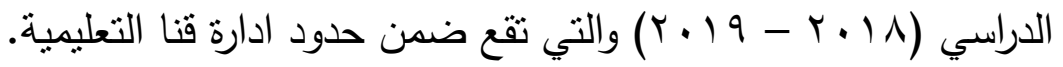
عينة الاراسة: تضمت عينة الدراسة عدد (VY) تلميذة من تلميذات الصف الاول الاعدادي بمدرسة الاعدادية بنات بقنا موزعات على شعبتين، شعبة (V/l) كمجموعة تجريبية والبالغ عددها (ب) طالبة ، وشعبة (r/l) كمجموعة ضابطة

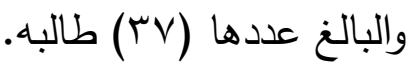


اثر إستخدام إستراتيجية محطات التعلم في تنمية الأستيعاب المفاهيمي في العلوم لدي تلاميذ المرحلة الإعدادية

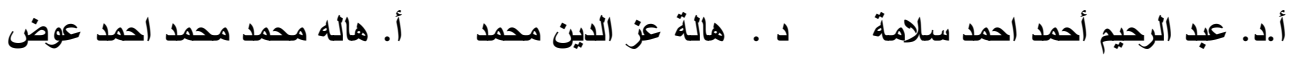

$$
\text { r ب. منهج الدراسة: }
$$

استخدمت الدراسة الحالية المنهج التجريبي القائم على تصميم المعالجات

التجريبية القبلية والبعدية من خلال المجموعات التالية:

- - المجموعة التجريبية: وتضم مجموعة من طالبات الصف الاول الاعدادئ الذين

بدرسون وحدة (الطاقة) موضوع التجربب وفق التدربس باستراتيجية محطات

التعلم.

- ـ المجموعة الضابطة: عينة من طالبات الصف الاول الاعدادئ الذين يدرسون

$$
\text { نفس الوحدة بالطربقة المعتادة. }
$$

". متغيرات الاراسة: تقتصر الدراسة الحالية على المتغيرات التالية:

المتغيرات المستقلة: المتغير المستقل في هذه الدراسة هو طريقة التدريس،

حيث درست المجموعة التجريبية باستخدام استراتيجية محطات التعلم، والمجموعة

الضابطة بالطريقة المعتادة.

المتغيرات التابعة: المتغير التابع في هذه الدراسة بتمنث في:

مدى الاستيعاب المفاهيمي لتلاميذ المرحلة الاعدادية " عينة الدراسة" في وحدة

" الطاقة " كما يقيسه الاختبار المعد لذلك.

$$
\text { ؛. ضبط المتغيرات الضابطة: }
$$

قامت الباحثة بضبط بعض المتغيرات للتحقق من تكافؤ المجموعتين قبل

$$
\begin{aligned}
& \text { تطبيق تجربة الدراسة وهي: } \\
& \text { - التحصيل القبلي في مادة العلوم. } \\
& \text { - - - العمر الزمني }
\end{aligned}
$$

ومن خلال الاحصاءات تم التوصل الي انه لا يوجد فرق ذو دلالة احصائية بين التلميذات في المجموعتين، وبذللك يمكن التأكد من تكافؤ مجموعتي الدراسة في تلاك المتغيرات. 
اثر إستخدام إستراتيجية محطات التعلم في تنمية الأستيعاب المفاهيمي في العلوم لدي تلاميذ المرحلة الإعدادية

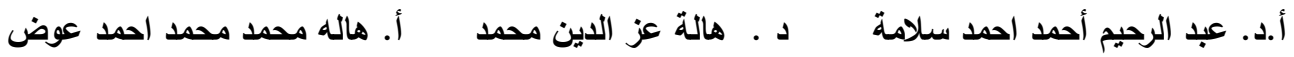

\section{• م. تطبيق تجربة الدراسة:}

للإجابة عن سؤال الدراسة واختبار صحة فرضها تم تدريس وحدة "الطاقة" للمجموعتين التجريبية والضابطة على النحو التالي: بالنسبة للمجموعة التجريبية:

قامت معلمة الصف بالتدريس للمجموعة التجريبية باستخدام دليل المعلمة وكتيب أوراق عمل الطالبات المعدين وفقاً لاستراتيجية محطات التعلم. بالنسبة للمجموعة الضابطة : تم تدربس الوحدة للمجموعة الضابطة بواسطة معلمة الصف (V/l) باستخدام الطريقة التقليدية المعتادة والتي تعنمد على الثرح والتلخيص والمناقثة وعلى استخدام بعض الأنشطة والعروض العملية من قبل المعلمة. هذا وقد بدأت تجربة الدراسة يوم الاحد ـ/ • 19/1 • م م، وتم الانتهاء من

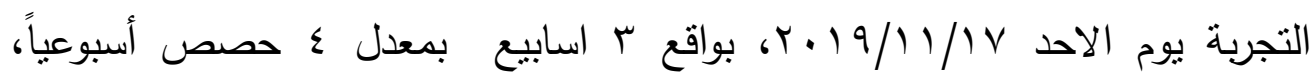
وبواقع (0 ؛ دقيقة) للحصة الواحدة. 7 ـ. التطبيق البعدى لأدوات الاراسة

بعد الانتهاء من تدربس الوحدة المقررة لمجموعتي الدراسة تم تطبيق أداة الدراسة والمتمثلة في اختبار الاستيعاب المفاهيمي على المجموعتين التجريبية

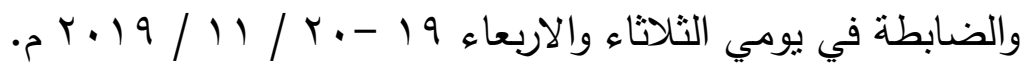
V . المعالجة الإحصائية

بعد تصحيح التطبيق ابعدي لاختبار الاستيعاب المفاهيمي تم رصد الدرجات ومعالجتها باستخدام الأساليب الإحصائية المناسبة من خلال البرنامج الإحصائي) SPSS ) 
اثر إستخدام إستراتيجية محطات التعلم في تنمية الأستيعاب المفاهيمي في العلوم لاي تلاميذ المرحلة الإعدادية

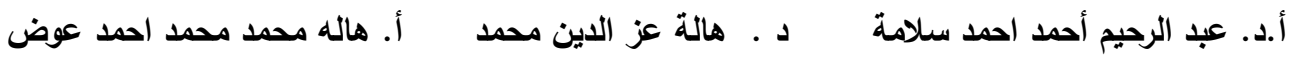

$$
\text { نتائج الاراسة وتفسيرها:- }
$$

فيما يلي عرض للنتائج التي تم التوصل إلبها للإجابة على سؤال الدراسة

وللتحقق من صحة فرضها.

ينص سؤال الدراسة علي مايلي: ما أثر استخدام إستراتيجية محطات التعلم

علي تتمية الاستيعاب المفاهيمي لدى تلاميذ المرحلة الاعدادية؟ ولإجابة عن هذا السؤال قامت الباحثة بالتحقق من صحة الفرض التالي الذي بنص على أنه: "لا يوجد فرق ذو دلالة إحصائية عند مسنوى ( متوسطي درجات تلميذات المجموعة التجريبية اللاتي درسن باستخدام استراتيجية محطات التعلم والمجموعة الضابطة التي درست بالطريقة المعتادة في التطبيق البعدي لاختبار الاستيعاب المفاهيمي في مادة العلوم". وللتحقق من صحة الفرضية تم استخدام اختبار "ت" لعينتين مستقلتين للكثف عن دلالة الفرق بين متوسطات درجات تلميذات المجموعة التجريبة والمجموعة الضابطة في النطبيق البعدي لاختبار الاستيعاب المفاهيمي، والجدول(ب) يوضح ذلك: 
اثر إستخدام إستراتيجية محطات التعلم في تنمية الأستيعاب المفاهيمي في العلوم لدي تلاميذ المرحلة الإعدادية

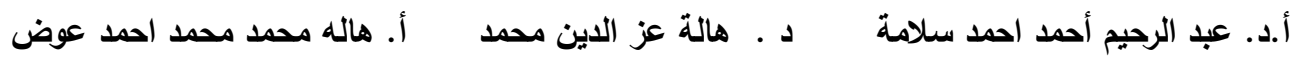

$$
\text { جدول (r) }
$$

نتائج اختبار"ت" لعينتين مستقلتين للمقارنة بين متوسطات درجات تلميذات مجموعتي الاراسة في التطبيق البعدي لاختبار الاستيعاب المفاهيمي

\begin{tabular}{|c|c|c|c|c|c|c|c|}
\hline مستوى الدلالة & قيمة (ت) & الحرية & الانحراف & التباين & المستوسطي & العينة & المجموعة \\
\hline دال & \multirow{2}{*}{$\bullet, \Gamma \wedge$} & \multirow{2}{*}{$v$. } & $\varepsilon, Y_{0}$ & $7,0 \leq$ & $r \wedge, 01$ & ro & التجريبية \\
\hline احصائيا & & & $0, .1$ & $11, \wedge v$ & $r Y, O\}$ & $\mu v$ & الضابطة \\
\hline
\end{tabular}

قيمة (ت) الجدولية عند درجة حرية (•V) عند مستوي دلالة (0.. (•) تساوي

$$
\cdot(1,99 \varepsilon)
$$

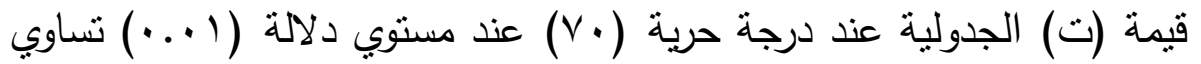

$$
\cdot(r, \neg \leqslant \Lambda)
$$

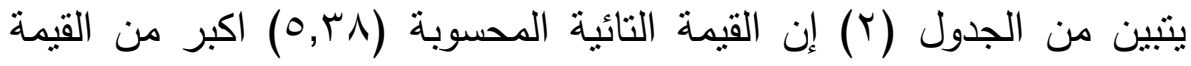

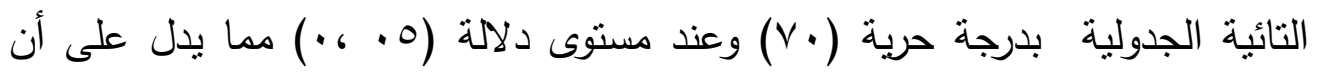
هناك فرق ذو دلالة إحصائية بين متوسط درجات الطالبات مجموعتي الدراسة ولصالح المجموعة التجريبية. حساب حجم تأثير المتغير المستقل على المتغير التابع: يمكن قياس قوة تأثير المعالجة التجريبية (استراتيجية محطات التعلم) على المتغير التابع (الاستيعاب المفاهيمي) بهدف تحديد درجة تأثنير المتغير المستقل على

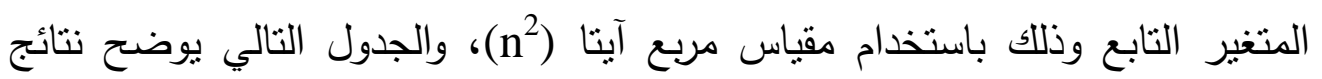
العمليات الإحصائية لحساب درجة تأثير المتغير المستقل على المتغير التابع. 
اثر إستخدام إستراتيجية محطات التعلم في تنمية الأستيعاب المفاهيمي في العلوم لاي تلاميذ المرحلة الإعدادية

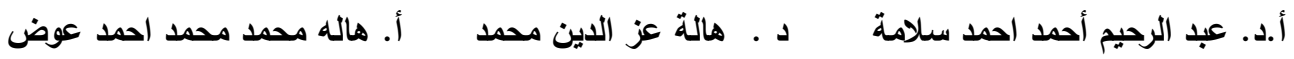

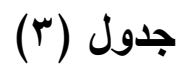

\section{قيمة مريع ايتا (}

\begin{tabular}{|c|c|c|c|}
\hline |درجة التأثير & قيمة & المتغير التابع & المتغير المستقل \\
\hline كبير & $\cdot, r 9$ & الاستيعاب المفاهيمي & استراتيجية محطات التعلم \\
\hline
\end{tabular}

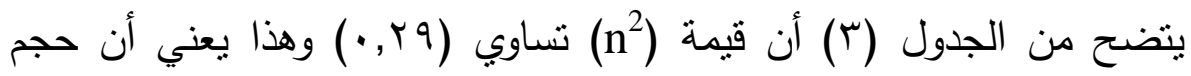
التأثير كبير مما يدل علي ان المتغير المستقل( استراتيجية محطات التعلم) له نأثير علي المتغير التابع (تتمية الاستيعاب الدفاهيمي) بدرجة كبيرة لصالح نتائج النطبيق

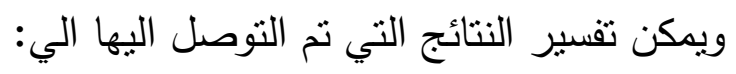

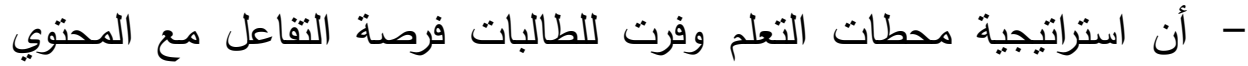
العلمي الذي يتعلمونه، فهن لم يحصلن علي المعلومات والدفاهيم بصورة جاهزة كما في الطريقة التقليدية وانما عن طريق تحوالهم بين الدحطات اذ يقومون

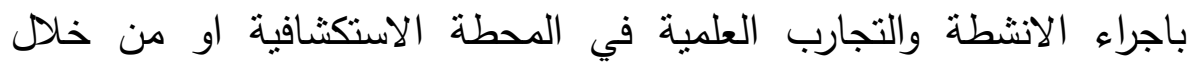

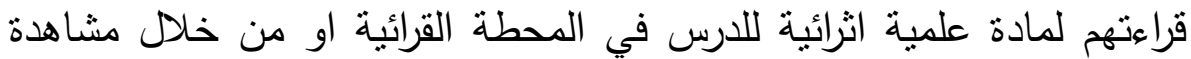

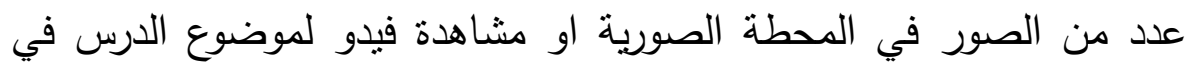

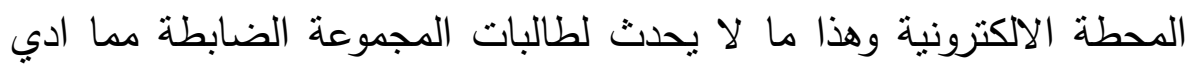

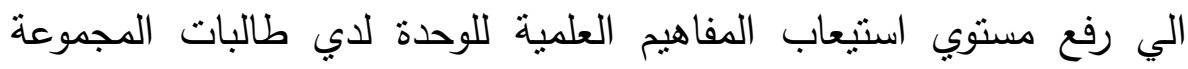
التجريبية. - تسمح محطات التعلم للطالبات باستخدام كافة حواسهن اثناء تتفيذهن للانثطة التعليمية، وتجعلهن بمارسن عمليات الاستقصاء والاستكثاف وتساعدهن على

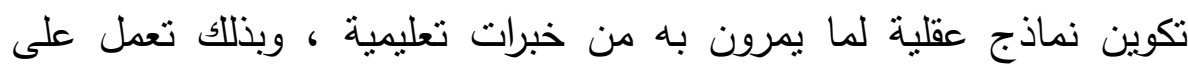

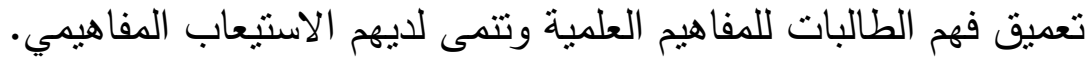


اثر إستخدام إستراتيجية محطات التعلم في تنمية الأستيعاب المفاهيمي في العلوم لدي تلاميذ المرحلة الإعدادية

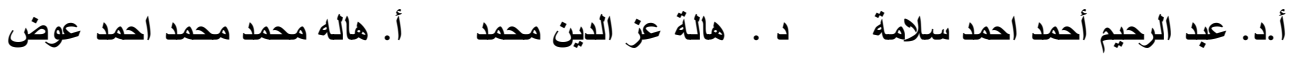
- أناحت محطات التعلم للطالبات فرصة التجول والانتقال بين المحطات المختلفة، حيث توفر لهن فرصة التساؤل والحوار والنقاش وتبادل الافكار في تردي مجموعات التعلم. - استراتيجية محطات التعلم بأنواعها المختلفة كانت عامل جذب للطالبات ، مما ولد لديهن الرغبة في استقصاء المعلومات والمفاهيم ، والرغبة في المناقنة وتوليد الافكار الجديدة، وهذا انعكس بالايجاب علي استيعابهن للمفاهيم العلمية الواردة بالوحدة المختارة. - دراسة وحدة الطاقة باستراتيجية محطات التعلم أدي الي تحسن مستوي الطالبات في المجموعة التجريبية في معرفة وفهم المفاهيم العلمية حيث مثلت لهم هذه الاستراتيجية نوع من المتعة بممارسة التعلم. - مرور الطالبات بالعديد من المحطات المختلفة اللاتي يمارسن خلالها العديد من الانشطة التعليمية بأنفسهن ويكتشفن خلالها المفاهيم ويربطنها بما لديهن من معرفة ، مما يؤدي الي تكامل المعلومات في اذهانهن مما يزيد من التحسن في استيعاب المفاهيم العلمية. - كما أن مرور الطالبات في المجموعة التجريبية بأنواع مختلفة من المحطات يكتشفن من خلالها المفاهيم يؤدي الي تتوع في الخبرات المعرفية لديهن، فتلك هون محطة استكثافية، واخري صورية، وثالثة الكترونية ورابعة قرائية.

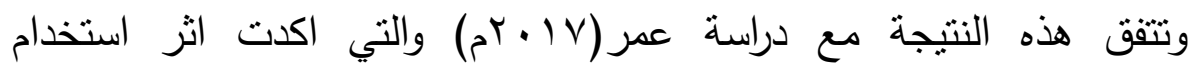
استراتيجية المحطات التعليمة في تتمية الاستيعاب المفاهميمي في الاحياء لاى طلاب الصف الاول الثانوي، ودراسة الاحمد والجهيمي (10 (10) والتي اثتتت فعالية استراتيجية التعليم المتمايز وفق نموذج الفورمات في تتمية الاستيعاب المفاهميمي في

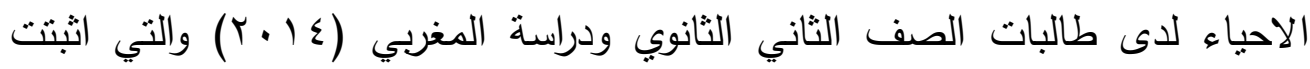
فعالية برنامج الكتروني قائم علي استراتيجية التعليم المتمايز في تتمية الاستيعاب المفاهميمي في مادة الحديث لدى طالبات الصف السادس الابتدائي وتتفق نتائج هذه 
اثثر إستخدام إستراتيجية محطات التطلم في تنمية الأستيعاب المفاهيمي في العلوم لاي تلاميذ المرحلة الإعدادية

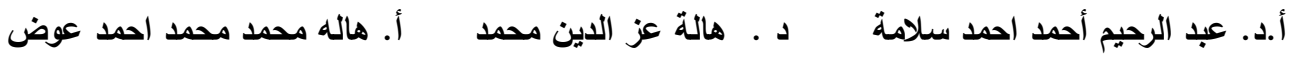

الفرضية مع نتائج العديد من الدراسات التي اكدت فعالية استخدام المحطات التعليمة في تحقيق بعض اهداف تدريس العلوم منل تتمية الوعي البيئي (Gercek\&Ozcan,2016) دراسة سليمان (10 +r م) ورفع مستوى التحصيل المعرفي ومهارات التفكير الابداعي في العلوم( زكي،با.ب) ورفع مستوى التحصيل والذكاء البصري المكاني

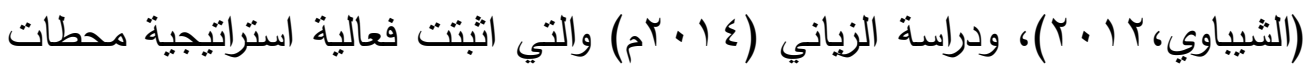
التعلم في تتمية مهارات التقكير التأملي ، ودراسة حسن (r ( ب rم) والتي اثتت فعالية استراتيجية محطات التعلم في حل المسائل الرياضية والميل نحو المادة، ودراسة كل من

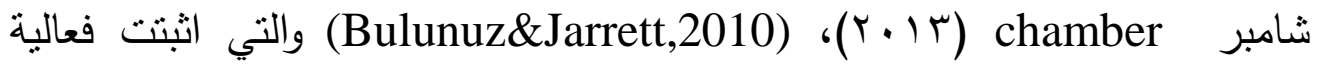
استراتيجية محطات التعلم في تصحيح المفاهيم الخاطئة، ورفع مستوي التحصيل

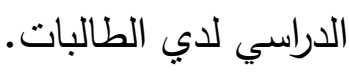
تعقيب علي النتائج:

ترى الباحثة أن النتائج أسفرت عن وجود فرق دال إحصائيا بين منوسط درجات طالبات المجموعة التجريبية ومنوسط درجات طالبات المجموعة الضابطة في الاختبار البعدي للاستيعاب المفاهيمي، وهذا يدل على نجاح استراتيجية محطات التعلم في تتمية الاستيعاب المفاهيمي لطالبات المجموعة التجريبية ويتضح من النتائج أيضًا أنه يجب الأخذ بعين الاعتبار عند تصميم أساليب واستراتيجيات التدريس التمايز والاختلاف بين الطالبات ومن ثم يجب تقديم استراتيجيات تحقق التمايز بينهم ومن بينها استراتيجية محطات التعلم. كما ترى الباحثة ضرورة تطوير استراتيجيات تدريسية جديدة وبحيث تعمل هذه

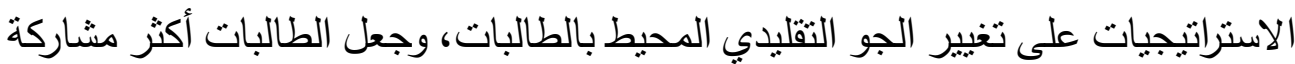
وفاعلية في العملية التعليمية التعلمية. 
اثر إستخدام إستراتيجية محطات التعلم في تنمية الأستيعاب المفاهيمي في العلوم لدي تلاميذ المرحلة الإعدادية

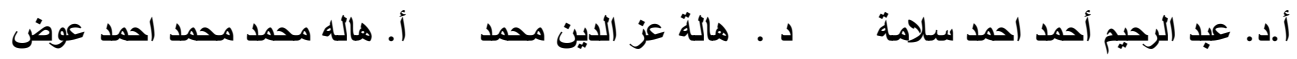

التوصيات والمقترحات:

توصيات الدراسة:

بناءً على نتائج البحث سابقة الذكر ، توصى الباحثة بما يلي:

'. تدريب معلمي العلوم قبل الخدمة على كيفية استخدام إستراتيجية المحطات العلمية

فى تدريس العلوم بمراحل التعليم المختلفة.

r. تقديم دورات تدريبية للمعلمين أثناء الخدمة حول كيفية استخدام إستراتيجية

المحطات العلمية؛ للاستفادة منها خاصة في المدارس ذوى الموارد المحدودة. r. ضرورة الاهنمام بتتمية عمليات العلم، والتفكير الإبداعي، وكذلك تتمية الدافعية نحو تعلم العلوم.

ع. إعادة النظر في طرق، وأساليب، وإستراتيجيات التدريس المتبعة في تدريس العلوم بالمرحلة الابتدائية، واستخدام طرق وأساليب وإستراتيجيات تدريس حديثة تشجع وابئي على ممارسة الأنشطة التعليمية وتثير الدافعية نحو تعلم العلوم.

البحوث المقترحة:

ا. دراسة أثز استخدام إستراتيجية المحطات العلمية في تدريس العلوم في تتمية

التفكير الناقد، ومهارة اتخاذ القرار لاى طالبات المرحلة الإعدادية.

r. دراسة أثز استخدام إستراتيجية المحطات العلمية في تدريس العلوم في ضوء

نظرية الذكاءات المتعددة، ودراسة أثرها على تتمية المهارات العلمية والدافع

لـانجاز

r. دراسة أثز استخدام إستراتيجية المحطات العلمية في تدريس العلوم في تتمية حب الاستطلاع، وتعديل التفضيل المعرفي لدى طالبات الصف الأول

الثانوي. 
اثر إستخدام إستراتيجية محطات التعلم في تنمية الأستيعاب المفاهيمي في العلوم لاي تلاميذ المرحلة الإعدادية

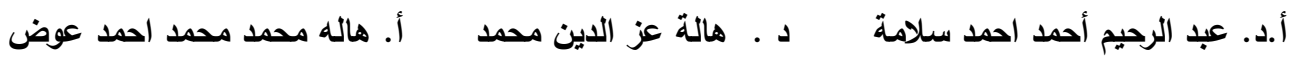

\section{المراجع:

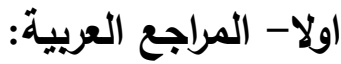

الاحمد، نضال والجهيمي، امل (10 بـ)، فاعلية استراتيجية التعليم المتمايز وفقا

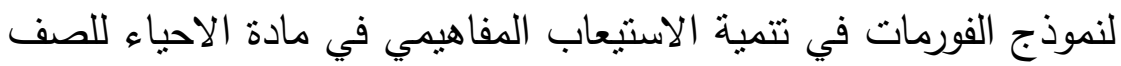
الثاني الثانوي بمدينة الرياض، مؤتمر التميز في تعليم العلوم والرياضيات الاول (STEAM)؛ السعودية ،جامعة الملك سعود.

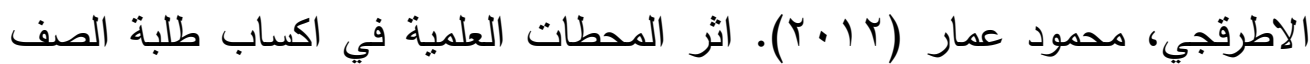
الثاني المتوسط المفاهيم الحاسوبية وتتمية تفكيرهم الاستدلالي، رسالة ماجستير غير منشورة، كلية التربية،جامعة الموصل، العراق.

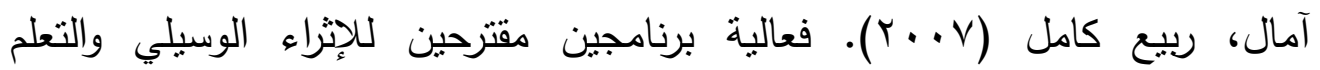

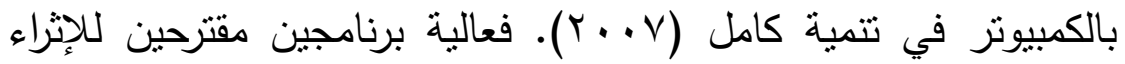
الوسيلي والتعلم بالكمبيوتز في تتمية بعض مهارات عمليات العلم

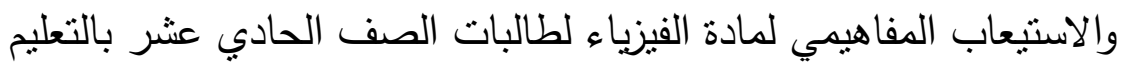
العام بسلطنة عمان، مجلة القراءة والمعرفة، الجمعية المصرية للقراءة والمعرفة، العدد ^جا، يوليه.

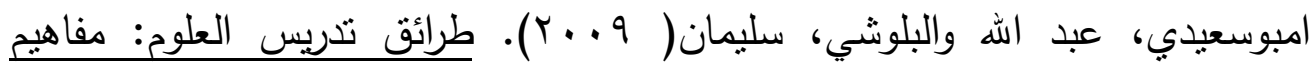
وتطبيقات عملية، دار المسيرة :عمان.

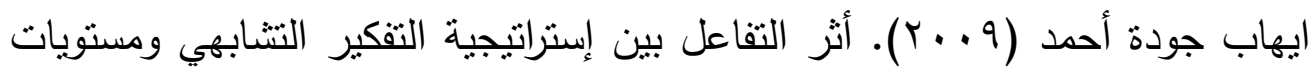
تجهيز المعلومات في تحقيق الفهم المفاهيمي وحل المسائل الفيزيائية لاىى

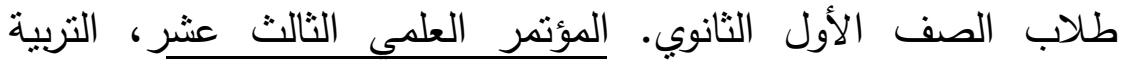
العلمية: المنهج والمعلم والكتاب دعوة للمراجعة، الجمعية المصرية للتربية

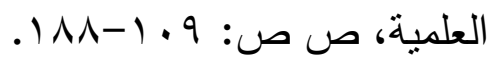

الباوي، ماجدة، والثمري، ثاني(10 (1) .أثز استراتيجية المحطات العلمية في تتمية عمليات العلم لدي طالبات معاهد إعداد المعلمين. مجلة جامعة كركوك

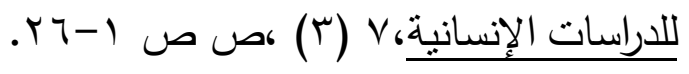


اثر إستخدام إستراتيجية محطات التعلم في تنمية الأستيعاب المفاهيمي في العلوم لاي تلاميذ المرحلة الإعدادية

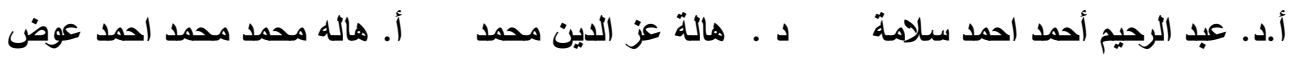

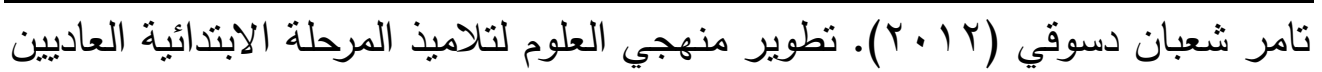

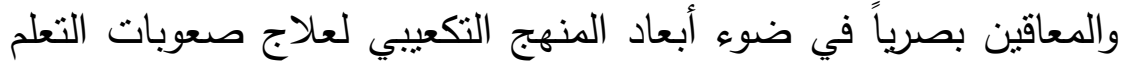
وتتمية الاستيعاب المفاهيمي وبعض مهارات عمليات العلم، دكتوراه، كلية

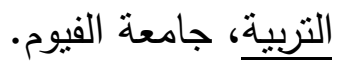

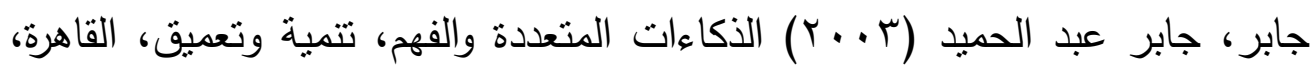
دار الفكر العربي.

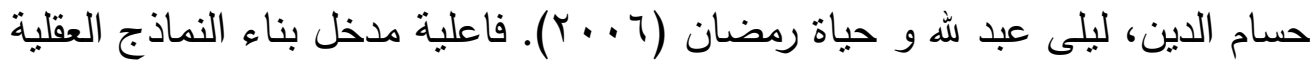

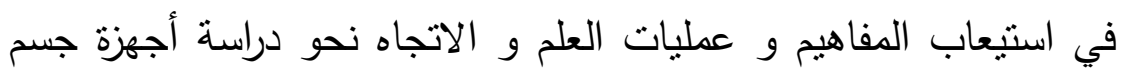

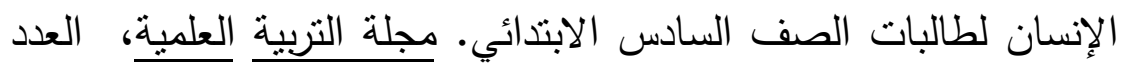

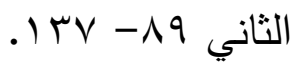

حسن، وردة (r ( • ب)، فاعلية إستراتيجية المحطات العلمية في حل المسائل الرياضية والميل نحو المادة لدي طالبات الصف الخامس الابتدائي، رسالة ماجستير غير منشورة، كلية التربية الأساسية، الجامعة المستتصرة، بغداد.

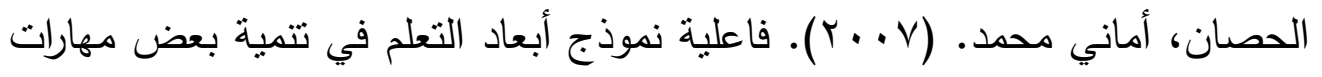

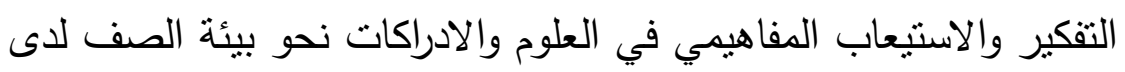
تلميذات المرحلة الابتدائية. رسالة دكتوراه غير منشورة. كلية التربية، جامعة الملك سعود.

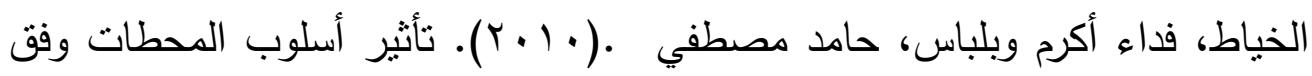
التعلم التعاوني والذاتي في اكتساب بعض المهابر الدهارات الأساسية بكرة اليد

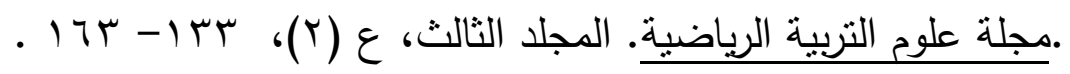

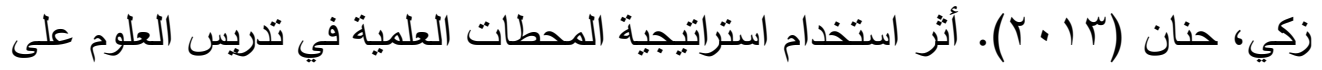
تتمية التحصل المعرفي وتتمية عمليات العلم والتفكير الابداعي والدافعية نحو تعلم العلوم لدي طالبات الصف الرابع الابتدائي، مجلة كلية التربية

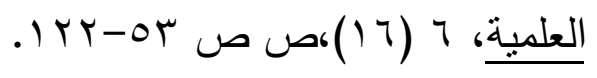


اثر إستخدام إستراتيجية محطات التعلم في تنمية الأستيعاب المفاهيمي في العلوم لاي تلاميذ المرحلة الإعدادية

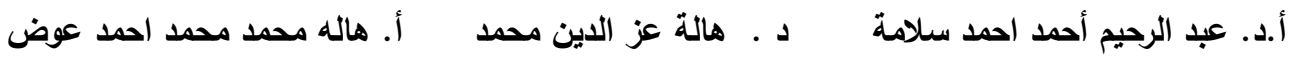

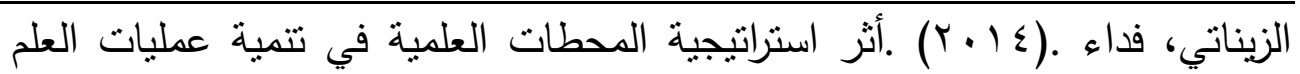

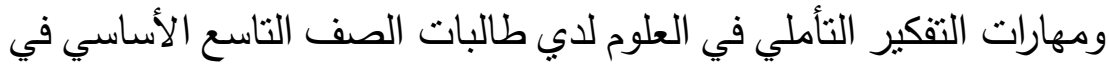
خانيونس، رسالة ماجستير غير منشورة، غزة، فلسطين.

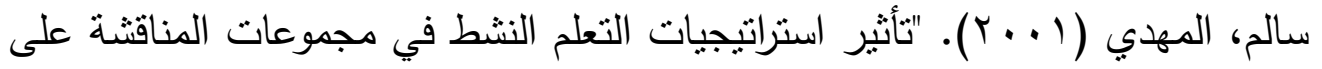

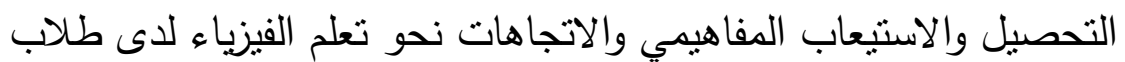

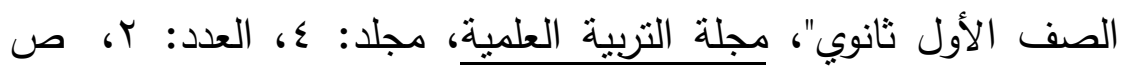

$$
\text { ص: }
$$

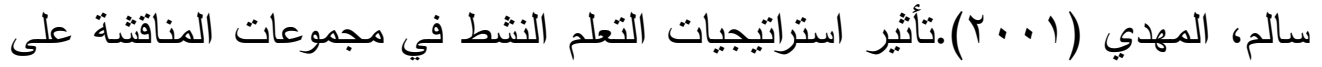

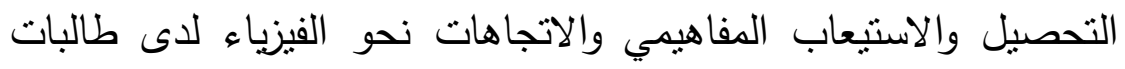

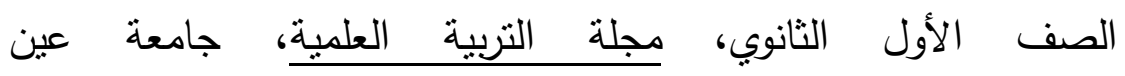

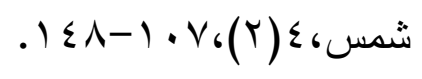

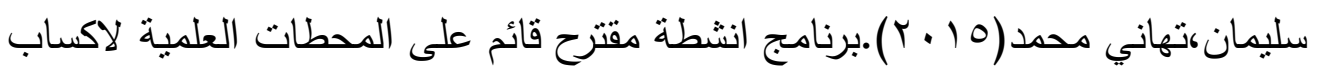

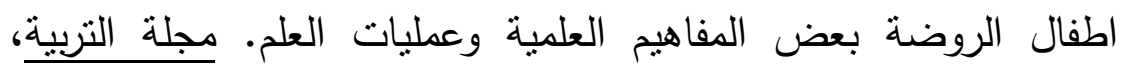

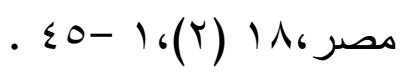

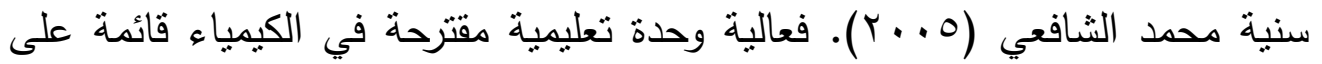
التصميم الارتجاعي في تحقيق الفهم العلمي لتلاميذ المرحلة الثانوية، المؤتمر العلمى التاسع "معوقات التربية العلمية في الوطن العربي:

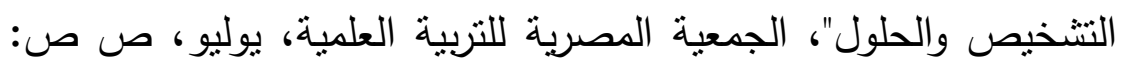

$$
. T Y V-191
$$

الثافعي، سنية محمد (0 ب). فعالية وحدة مقترحة في الكيمياء قائمة على التصميم

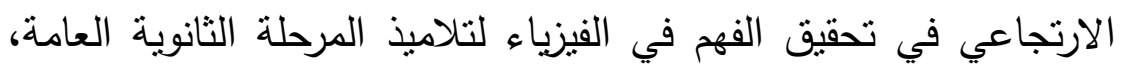
المؤتمر العلمى التاسع للجمعية المصرية للتربية العلمية، معوقات التربية

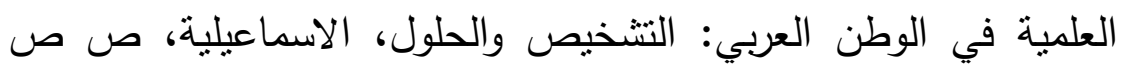

$$
\text { .rYA-191 }
$$

الثمري، ثاني حسين (1) (Y). أثز إستراتيجيتي المحطات العلمية ومخطط البيـت الدائري في تحصيل مادة الفيزياء وتتمية عمليات العلم لدى طالبات معاهد الفئي 
اثر إستخدام إستراتيجية محطات التعلم في تنمية الأستيعاب المفاهيمي في العلوم لدي تلاميذ المرحلة الإعدادية

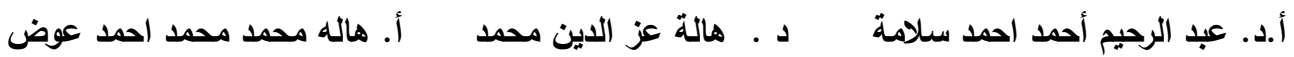
إعداد المعلمين," رسالة دكتوراه غير منثورة، كلية التربية ابن الهيثم، جامعة بغداد ، بغداد. الثون، هادي، الثيباوي، ماجد(ب ا • Y). فاعلية التدريس باستراتيجية المحطات العلمية في الذكاء البصري المكاني في الفيزياء لدي طالبات الصف الاول الثانوي،

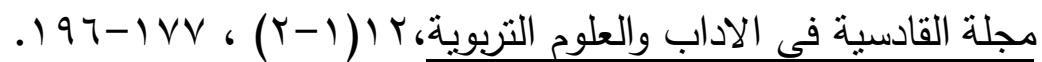

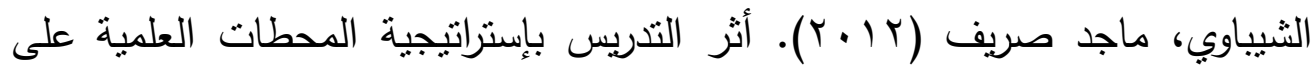
التحصبل والذكاء البصري المكاني في الفيزياء لدى طالبات الصف الأول المتوسط"، رسالة ماجستير غير منشورة، كلية التربية، جامعة القادسية، القادسية. الطويرقي، حنان محمد عابد (T ( ب). التدريس المتمايز، مكتبة خوارزم العلمية، جدة.

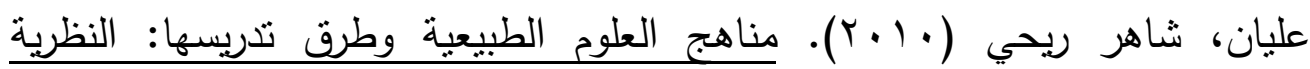
والتطبيق ، دار المسيرة للنشر والتوزيع ، عمان الأردن.

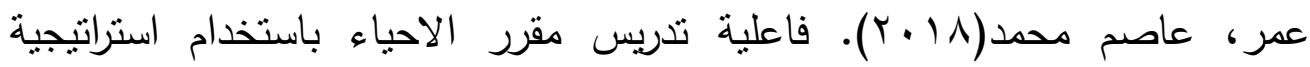
محطات التعلم فيتتمية اليقظة الذهنية والاستيعاب المفاهيمي لدى طلاب الصف الاول الثانوي.مجلة الدراسات التربوية والنفسية، جامعة السلطان

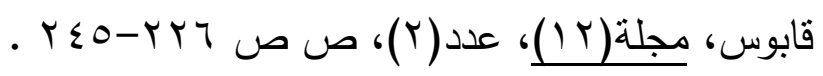

العنبكي، وفاء.(ع 1 • Y). أثز التدريس باستراتيجية المحطات العلمية علي التحصيل والاستبقاء في مادة العلوم العامة لدي طالبات الصف الخامس الابتذائي

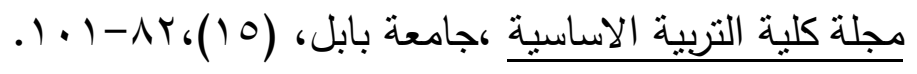

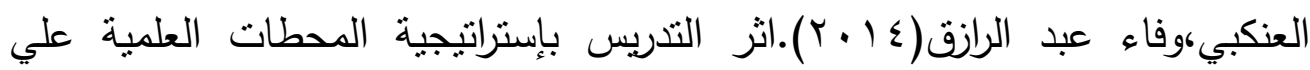
التحصبل والاستبقاء في مادة العلوم العامة لدي طالبات الصف الخامس الابتدائي، مجلة كلية التربية الأساسية، جامعة بابل، العدد (0) (10).

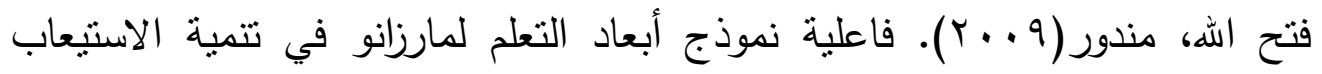
المفاهيمي في العلوم وعادات العقل لدى تلاميذ الصف السادس الابتذائي بالمملكة العربية السعودية، رسالة ماجستير غير منشورة. كلية التربية، جامعة القصبم. 
اثر إستخدام إستراتيجية محطات التعلم في تنمية الأستيعاب المفاهيمي في العلوم لاي تلاميذ المرحلة الإعدادية

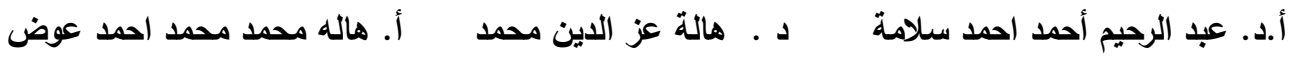
كوجك، كوثز وآخرون (1 . . r). تتويع التدريس في الفصل: دليل المعلم لتحسين طرق التعليم والتعلم في الوطن العربي، بيروت : مكتب اليونسكو الإقليمي للتربية في الدول العربية.

اللهيبي، عبد الرازق عبادة.(10 ( 10)، أثز استخدام المحطات العلمية في تحصيل طالبات الصف الثاني المتوسط واتجاههم نحو مادة الفيزباء، مجلة الفتح

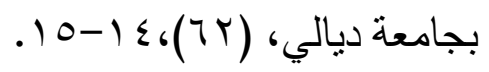

مصطفى، محمد نجيب (T . . Y). طرق تدريس العلوم بين النظرية والتطبيق، الرياض: مكتبة الرشد.

المغربي، سامية (ع ( ؟). فعالية برنامج الكتروني قائم علي إستراتيجية التعليم المتمايز

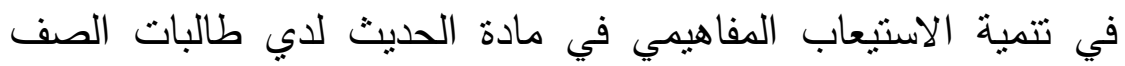
السادس الابتدائي في مدينة الرياض، رسالة ماجسنتير غير منشورة ،كلية

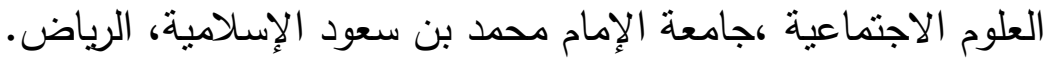

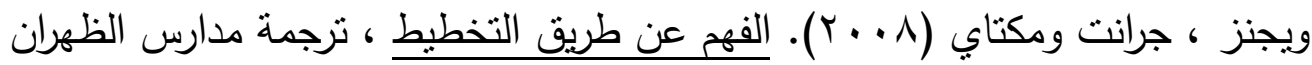
الأهلية، الدمام : دار الكتاب التربوي للنشر والتوزيع. 
اثر إستخدام إستراتيجية محطات التطلم في تنمية الأستيعاب الدفاهيمي في العلوم لاي تلاميذ المرحلة الإعدادية

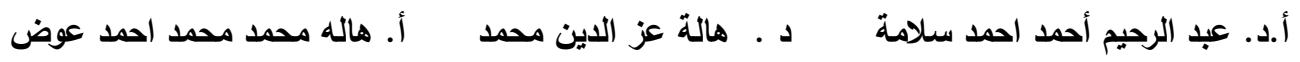

$$
\text { ثانيا: المراجع الاجنبية:- }
$$

Chambers, D. (2013). .Station Learning: Dose It Clarify Misconceptions On Climate Change And Increase Academic Achievement Through Motivation In Science Education (Unpublished Master's Thesis). Ohio University, USA.

Clement ,J.(2003) Model Based Learning as Key Research Area for Science Education ,International Journal of Science Education. (9)22,1041-1053.

Denise Jacques Jones.(2007). The Station Approach: How to Teach With Limited Resources, National Science Teachers Association, p. 16-21,. From: www.nsta.org/main/news/.../science_scope.php

Gerek,C., \& Ozcan,(2016). Determining the students views towards the learning stations developed for the environmental education. Problems of Education in the $21^{\text {St }}$ Century,69(1),29-36.

Hall, Z.; Arlene, M. \& Sydney, S. (2000). "The Effects of a Learning Station on the Completion and Accuracy of Math Homework for Middle School Students", Journal of Behavioral Education, Vol.(10), No.(2), pp.(123-137).

Heacox, Diane (2002) Differentiating Instruction in the Regular Classroom; How to reach and teach ALL learners, grades 3-12 by .Free spirit Publishing.

Kalkains ,G .et al .(2003).An Instructional Model for a Radical Conceptual Change towards Quantum Mechanics Concept, Science Education, 87 (2), 257- 280.

Nermin , Bulunuz \& olga , Jarrett, (2010), The effect of hands on learning stations on building American elementary 
اثر إستخدام إستراتيجية محطات التطلم في تنمية الأستيعاب الدفاهيمي في العلوم لاي تلاميذ المرحلة الإعدادية

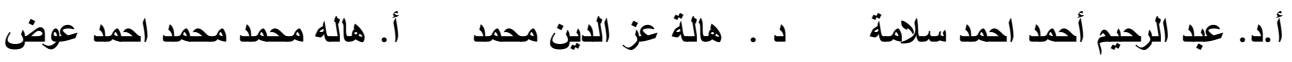

teachers understanding about earth and space science concepts , Eurasia journal of mathematics, science, Technology education .

Ocak ,G . (2010,Janyary). The Effect of Learning Stations on the Level of Academic Success and Retention of Elementary School Students. The New Educational Review, 21 (2), 146-156.

Russell, T. (2002). Teaching for Understanding in Science, Students Conceptions Research, and Changing Views of Learning. Australian Science Teachers Journal, 48(3) 14-16. 